\title{
Research on Landing Gear Metering Pin and Analysis of its Impact on the Buffer Performance
}

\author{
Dinagara Aroulen Vencatasawmy \\ College of Aerospace Engineering \\ Nanjing University of Aeronautics \& Astronautics \\ Nanjing, 210016, China
}

\author{
Dr. Xue Caijun \\ College of Aerospace Engineering \\ Nanjing University of Aeronautics \& Astronautics \\ Nanjing, 210016, China
}

\begin{abstract}
Buffer performance system or the resistance force of a landing gear mechanical structure is one of the key points for aircraft landing gear design as not only does it provide structural strength but it also ensures smooth landing and a reduction of fuel consumption. This paper investigates the possibility of improving the effectiveness of the buffer performance of a landing gear with a new metering pin design. The shape of the metering pin inside the shock absorber affects directly the buffer absorption efficiency and buffer absorption power. The objective of this research is to gather previous data of existing shock absorbers, analyse its influence throughout different parameters and come up with a new possible improved metering pin design to determine how the efficiency is affected. A new ideal approach to investigate the impact of a new metering pin device on shock absorption efficiency of a landing gear is proposed.
\end{abstract}

Keywords-Buffer performance; metering pin; shock absorber; efficiency; landing gear.

\section{INTRODUCTION}

Aircraft landing gear is one of the most fundamental components of an aircraft as it handles its entire load during the process of landing and grounding procedures which impacts on flight safety. A suitable gear depends on the aircraft design and shock absorption during landings and take offs. In order to prevent the structural components from being damaged due to an overloaded aircraft during the take-off and landing process, the designed landing gear must be able to effectively absorb the energy generated during the landing.

The role of the shock absorber is to absorb and dissipate energy upon impact so that the forces imposed on the aircraft's frame are tolerable [1]. Oleo pneumatic shock absorbers are utilized mostly because of its effectiveness of reduced forces transferred to the aircraft from the impact during landing, as well as from the disturbance due to the disproportion of the taxiway. Currently, most aircraft utilize a passive oleopneumatic shock absorber because of its significant energy dissipation capacity compared to other shock absorbers, together with high strut efficiency and decent rebound control. Passive shock absorbers are commonly used in aircraft landing gears but can optimally be designed for specific conditions. However, passive shock absorbers cannot function optimally under conditions that differ from their specified conditions due to mass variation problems of passive shock absorbers. When an aircraft touches the ground, the landing gear bears a large impact load, which may damage its structure. Therefore, it is necessary to study the shock absorber of the landing gear during landing as it impacts directly its buffer performance.
A contrast between the calculated results and the drop-test data was evaluated to consider the mechanic model in this paper [2]. In reference [3] a research on the performance and efficiency of buffer absorption of a landing gear system was executed. It was concluded that the size of hydraulic flow of the fluid through the orifice area plays a major role on its efficiency.

Apart from passive devices, active and semi active control methods have also been proposed as aircraft shock absorbers. A theoretical analysis and experimental validations have been carried out to investigate the advantages of the actively controlled landing gears, such as in $[4,5]$. The landing gear system featuring electrorheological/magnetorheological fluids was theoretically evaluated in Reference [6]. Furthermore, detailed analysis of factors and parameters are available in the existing literature [7, 8, and 9].

The efficiency of the buffer absorption performance of a landing gear system is affected by its shock absorber which in turn is dependent on the hydraulic flow of the fluid through the orifice area. Implementing a new shape of metering pin can improve considerably the buffer efficiency. It is of uttermost necessity to make the landing gear with minimum load, less volume, high efficiency, more comfort, safety, enhanced life and reduction in life-cycle. Targeting an increase in efficiency of the buffer performance will reduce the structural damage of the struts and energy consumption (fuel). It will also improve drop test quality, landings, take-offs, passenger comfort and impact on the environment.

This paper provides an ideal procedure through which the buffer performance of a landing gear can be analysed. The aim is to evaluate the positive and negative impact of including a new shape of metering pin design in a simple shock absorber and to perform a comparison with the performance of a conventional shock absorber without a pin device.

\section{BUFFER SYSTEM}

The shock absorber system or the buffer system is often referred as the most essential part in the landing gear of an aircraft. The greatest fundamental function of shock absorber system including other segments of landing gear such as the tire is to act as an absorber of energy for landing impacts or any unpredictable shocks provoked and transferred to the aircraft fuselage while taxiing over disproportional surfaces. The landing touchdown cushion defines the maximum energy dissipation conditions for the shock absorber and rules its overall performance when comparing all the design operation conditions. Precisely, the aim is to disperse all the impact energy without instigating the aircraft to rebound and fulfil the 
design requirement while considering the greatest energy absorption efficiency and the minimum gear load signifying passenger/crew comfort.

At present, buffers are mainly divided into two basic types: solid spring shock absorbers made of steel or rubber, fluid spring shock absorbers made of oil, or mixtures of two media - oil and gas shock absorbers [10]. Oil and gas dampers have been widely used in aircraft because of their high cushioning efficiency that can generally reach $70 \%$ and their good power absorption capacity. To improve the landing performance of the oil and gas shock absorber, the designer made a large-scale design improvement on the internal and external structure of the shock absorber. In addition, a variable oil-hole design was included or a double-chamber structure was used in the buffer. As the number of improvements in the internal and external structure of the buffer decreases, more and more design methods and optimization tools can be used to optimize the buffer. Which design method or optimization tool can be used to obtain the optimal buffer parameters (single or double cavity buffer internal filling parameters, one-way or main oil hole diameter, metering pin etc.) to improve the landing buffer performance has gradually become one of the research hotspots.

In this research, we discuss about shock absorbers without (Fig. 1) and with metering pins (Fig. 3). Typically shock absorbers comprise of two compartments namely a steel cylinder and a flexible piston. Guide bearings are utilized to facilitate the movement between the piston's outer surface and the inner surface of the upper cylinder.

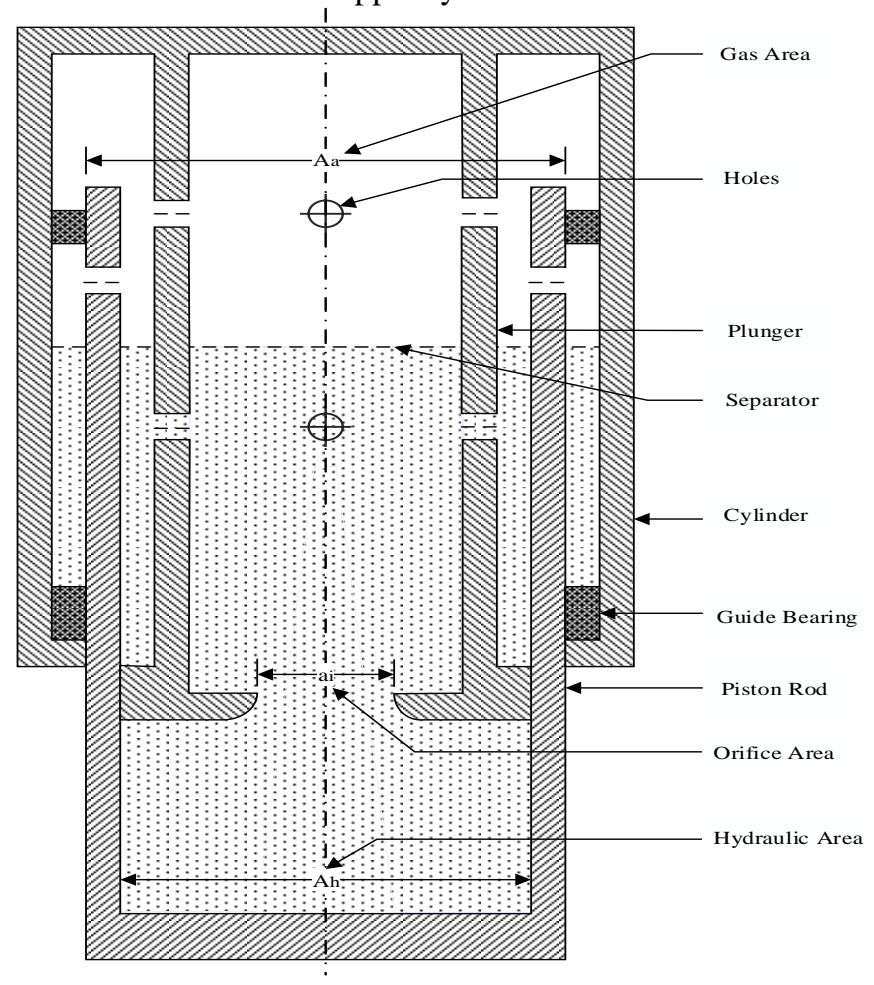

Fig. 1. A conventional passive shock absorber

As indicated in Fig. 1, the system's lower section (piston rod) is supplied with hydraulic liquid and the system's upper section (cylinder) is filled with a gas. The air is compressed by the fluid when the lower section rod passes throughout the upper section cylinder and this action creates a phenomenon that causes an elastic resistive motion.

The shock absorber is a unit combination consisting of a hydraulic damping system and an air-filled spring system. The piston rod acts as the pneumatic spring when it moves inside the upper section with respect to the fluids.

During landing of an aircraft, the lower component of the system (piston with the wheels) moves back and forth into the upper section (cylinder), filling partly the inner chamber with the damping liquid and compressing the gas. Such damping influence is possible due to the six holes in the chamber plunger allowing a cycle fluid flow inside the buffer. The plunger is linked to the sealing of the upper cylindrical section of the system. The shock absorber also consists of a main orifice area to regulate the flow of the fluid during extension and retraction of the lower section of the system. In order to augment the damping effect, back valves are utilized in the internal surface to obstruct the movement of the fluid into this space during reverse movement of the piston.

\section{A. Mechanical Model of the system}

In this section, a mechanical model of a landing gear is assembled and the resistant forces for a conventional oleopneumatic shock absorber are outlined. Certain assumptions regarding some factors were considered for simplicity. Constant damping orifice discharge coefficient and aircompression exponent were assumed in the nonlinear shock absorber model.

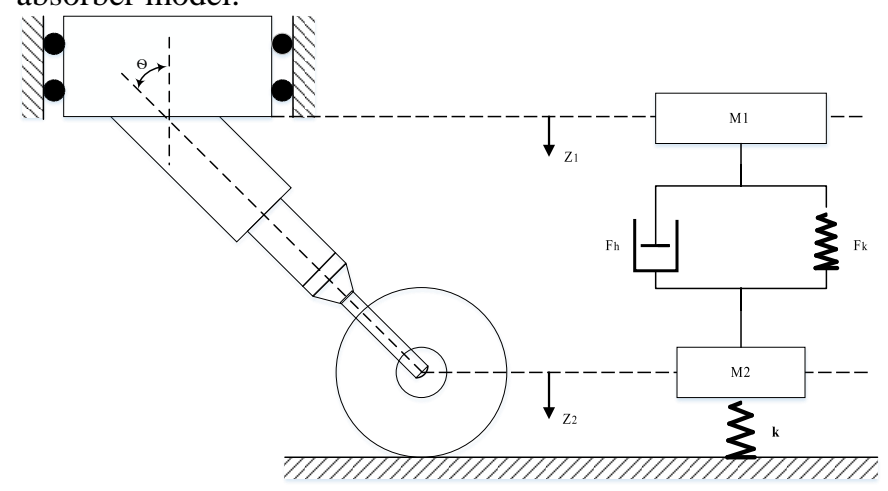

Fig. 2. Schematic of Landing gear model

A two-degree-of-freedom model shown in Fig. 2, is utilized to construct the landing characteristic of the landing gear (an altered version of figure 1a in [11]).

The total axial force or resistive force $\mathrm{f}_{\mathrm{s}}$ of the shock absorber is expressed as

$$
\mathrm{f}_{\mathrm{s}}=\mathrm{f}_{\mathrm{h}}+\mathrm{f}_{\mathrm{k}}
$$

Where, $\mathrm{f}_{\mathrm{h}}$ and $\mathrm{f}_{\mathrm{k}}$ denote the hydraulic damping force and air spring force respectively.

\section{B. Equation of Motion \& Resisting Forces}

The mass of the gear divides into an upper section and a lower section of the strut. $\mathrm{m}_{1}$ symbolises the entire upper section as well as the mass of the fuselage affecting the gear, and $\mathrm{m}_{2}$ characterizes the mass of the inferior section. The gravitational force acts directly on the masses $\mathrm{m}_{1}$ and $\mathrm{m}_{2}$ whereas lift affects both the masses. The equation of motion for the two-mass systems shown in Fig. 2, is expressed as 
When $0<z_{p}<z_{p \max }$, and as

$$
\ddot{\mathrm{z}}_{1}=-\mathrm{f} / \mathrm{m}_{1}, \ddot{\mathrm{z}}_{2}=\left(\mathrm{f}-\mathrm{kz}_{2}\right) / \mathrm{m}_{2}
$$

When $\mathrm{z}_{\mathrm{p}}=0$ or $\mathrm{z}_{\mathrm{p}}=\mathrm{z}_{\mathrm{p} \max }$

$$
\ddot{\mathrm{z}}_{1}=-\mathrm{kz}_{2}\left(\mathrm{~m}_{1}+\mathrm{m}_{2}\right), \ddot{\mathrm{z}}_{2}=\ddot{\mathrm{z}}_{1}
$$

Where, $\mathrm{m}_{1}$ signifies a mass load combination of travelers, freight, and fuel of a landing gear and $\mathrm{m}_{2}$ represents a mass load combination of tires and moving part of the shock absorber. $\mathrm{k}$ denotes the total spring constant of tires and $\ddot{\mathrm{z}}_{1}$ and $\ddot{\mathrm{z}}_{2}$ indicate a vertical acceleration of $\mathrm{m}_{1}$ and $\mathrm{m}_{2}$ respectively.

The vertical displacement of the two masses is denoted by the two degrees of freedom $z_{1}$ and $z_{2}$ respectively. The strut strokes $z_{p}$ identifies relative displacement in the stroke of the buffer and is expressed by

$$
\mathrm{z}_{\mathrm{p}}=\frac{\mathrm{z}_{1}-\mathrm{z}_{2}}{\cos \emptyset}
$$

The model is intended to seize the stroke of initial contact with the ground to the first point at which the relative velocity of the shock strut is slowed to zero. We state this point at the finish line of the landing process. Angle $\theta$ represents the rake angle of the strut.

The air spring resisting force of the shock absorber according to the polytrophic law is expressed as

$$
f_{K}=A_{a}\left(p_{o}\left(\frac{v_{o}}{v_{o}-A_{a} z_{p}}\right)^{\gamma}-P_{a}\right)
$$

Where, $A_{a}$ is the effective pneumatic area of the outer diameters of the shock absorber, $\mathrm{P}_{\mathrm{o}}$ is the initial air pressure in the upper chamber of strut, $\mathrm{v}_{\mathrm{o}}$ is the initial volume of gas. $\mathrm{p}_{\mathrm{atm}}$, denotes the standard atmospheric pressure. $\gamma$, represents the variability index of gas.

The hydraulic damping force due to dynamic pressure is expressed by

$$
\mathrm{f}_{\mathrm{h}}=\frac{\mathrm{A}_{\mathrm{d}}}{\mathrm{a}_{\mathrm{i}}} \times \dot{\mathrm{z}}_{\mathrm{p}}^{2}
$$

Where, $A_{d}$ represents the discharge coefficient factor, $a_{i}$ or $\mathrm{a}_{\mathrm{zp}}$ (with metering pin) the area of the main oil orifice and $\dot{\mathrm{z}}_{\mathrm{p}}^{2}$ is relative velocity of the buffer stroke. The discharge factor $A_{d}$ can be expressed as

$$
\mathrm{A}_{\mathrm{d}}=\frac{\rho \mathrm{A}_{\mathrm{h}}^{3}}{2 \mathrm{C}_{\mathrm{D}}^{2}}
$$

$A_{h}$, represents the area of the main hydraulic chamber, $C_{D}$ the flow coefficient of the oil hole, $\rho$ density of the hydraulic fluid.

\section{DESIGN MODEL FOR METERING PIN}

A typical shock absorber with an existing single modified tapered metering pin design is illustrated in [12]. A metering pin with a variable cross-section is linked to the lower piston.
The metering pin alters the flow occurrence of the fluid of the piston as it passes through the orifice hole.

As shown in fig. 3, the shock absorber is illustrated with an existing metering pin to illustrate how the flow of the fluid is affected and how the cross-sectional length of the pin plays an important role during impact on the landing tarmac.

The effective orifice area is given by

$$
\mathrm{a}_{\mathrm{zp}}=\mathrm{a}_{\mathrm{i}}-\frac{\pi}{4} \mathrm{D}_{\mathrm{zp}}^{2}
$$

Where, $\mathrm{a}_{\mathrm{i}}$ is the orifice area through which the metering pin design moves during landing. $a_{z p}$ denotes the remaining crosssectional area when the metering pin goes though the orifice area with respect to the displacement of $z_{p} . D_{z p}$ is the diameter of the new metering pin construction which is calculated in equation 9 and illustrated in fig. 4.

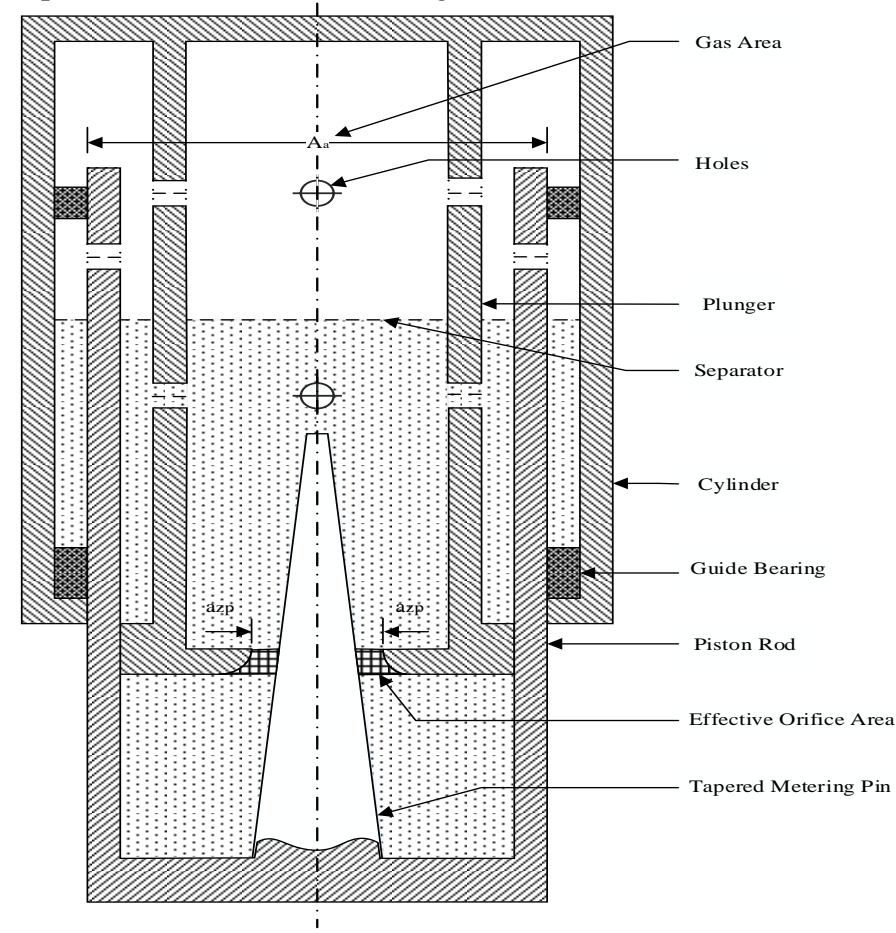

Fig. 3. Shock absorber with existing metering pin design

The orifice area $a_{i}$ in fig. 1 is not affected by the displacement of $z_{p}$. However the effective orifice area is directly affected by the displacement of $z_{p}$ as illustrated in fig. 3 . 

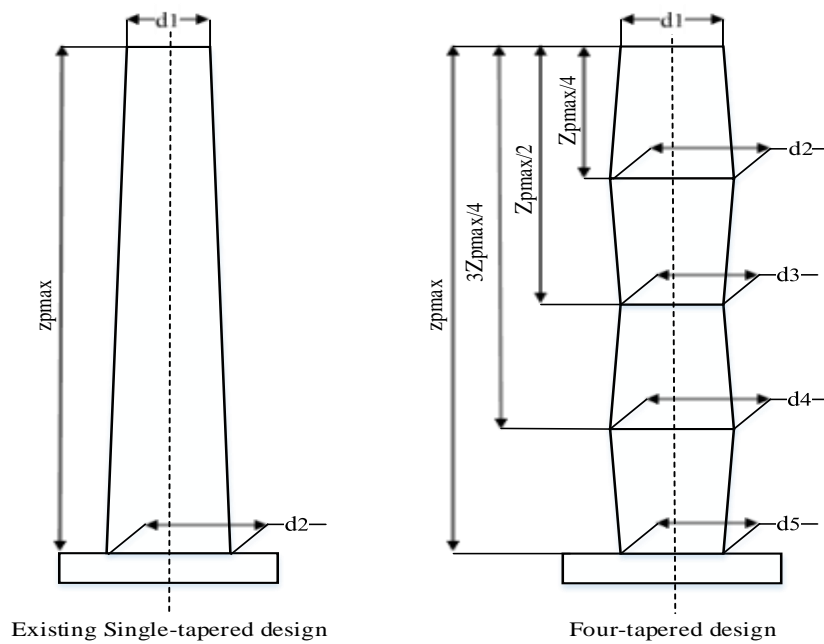

Fig. 4. Diagram of metering pin constructions

The metering pin is evenly distributed into four-tapered sections as shown in figure 4 . Each section has a specific diameter $D_{i}$ with $i_{\max }=5$. The diameter of the new metering pin with respect to the displacement of $z_{p}$ is given below When, $0 \leq z_{p} \leq z_{p \max } / 4$, the diameter is calculated as

$$
\mathrm{D}_{\mathrm{zp}}=\mathrm{d}_{1}+\frac{\left(\mathrm{d}_{2}-\mathrm{d}_{1}\right)}{\left(\mathrm{z}_{\mathrm{p} \text { max }} / 4\right)} \times \mathrm{z}_{\mathrm{p}}
$$

When, $0 \leq z_{p} \leq z_{p \max } / 4$, the diameter is calculated as

$$
\mathrm{D}_{\mathrm{zp}}=\mathrm{d}_{1}+\frac{\left(\mathrm{d}_{2}-\mathrm{d}_{1}\right)}{\left(\mathrm{z}_{\mathrm{p} \text { max }} / 4\right)} \times \mathrm{z}_{\mathrm{p}}
$$

When, $z_{p \max } / 4 \leq z_{p} \leq z_{p \max } / 2$, the diameter is calculated as

$$
\mathrm{D}_{\mathrm{zp}}=\mathrm{d}_{2}+\frac{\left(\mathrm{d}_{3}-\mathrm{d}_{2}\right)}{\left(\mathrm{z}_{\mathrm{p} \max } / 4\right)} \times\left(\mathrm{z}_{\mathrm{p}}-\mathrm{z}_{\mathrm{p} \max } / 4\right)
$$

When, $z_{p \max } / 2 \leq z_{p} \leq 3 z_{p \max } / 4$, the diameter is calculated as

$$
\mathrm{D}_{\mathrm{zp}}=\mathrm{d}_{3}+\frac{\left(\mathrm{d}_{4}-\mathrm{d}_{3}\right)}{\left(\mathrm{z}_{\mathrm{p} \max } / 4\right)} \times\left(\mathrm{z}_{\mathrm{p}}-\mathrm{z}_{\mathrm{p} \max } / 2\right)
$$

When, $3 z_{p \max } / 4 \leq z_{p} \leq z_{p \max }$, the diameter is calculated as

$$
D_{z p}=d_{4}+\frac{\left(d_{5}-d_{4}\right)}{\left(z_{p} \max / 4\right)} \cdot\left(z_{p}-3 z_{p \max } / 4\right)
$$

In this study, a suitable relationship for orifice areas is considered by outlining a detail sketch of lengths and diameters of the metering pin. The area of the hole as well as the resistance forces is observed with respect to the mass. The area of the orifice through which the damping liquid runs is affected by the new shape of the metering pin design.

The parameters of the landing-gear model and the passive shock absorber used in this study are summarized in Table 1.
Table 1. Parameter for landing gear

\begin{tabular}{|l|c|c|}
\hline \multirow{2}{*}{ Name } & \multicolumn{2}{c|}{ Parameter } \\
\cline { 2 - 3 } & Symbol & Units \\
\hline Rake angle & $\varnothing$ & Deg \\
\hline Fluid discharge coefficient factor & $\mathrm{A}_{\mathrm{d}}$ & $\mathrm{Kg} / \mathrm{m}^{3}$ \\
\hline Pneumatic area for inner shock absorber piston tube & $\mathrm{A}_{\mathrm{a}}$ & $\mathrm{m}^{2}$ \\
\hline Equivalent mass of upper landing gear & $\mathrm{M}_{1}$ & $\mathrm{Kg}$ \\
\hline Equivalent mass of lower landing gear & $\mathrm{M}_{2}$ & $\mathrm{Kg}$ \\
\hline Initial gas volume of landing gear buffer & $\mathrm{v}_{0}$ & $\mathrm{~m}$ \\
\hline Polytropic exponent for air-compression process & $\gamma$ & - \\
\hline Initial gas pressure of landing gear buffer & $\mathrm{p}_{\mathrm{o}}$ & $\mathrm{MPa}$ \\
\hline Atmospheric pressure & $\mathrm{p}_{\mathrm{atm}}$ & $\mathrm{MPa}$ \\
\hline Primary gear tire initial pressure & $\mathrm{p}_{\mathrm{t}}$ & $\mathrm{Mpa}$ \\
\hline Gravitational Constant & $\mathrm{g}$ & $\mathrm{m}^{3} / \mathrm{kgs}$ \\
\hline Aircraft descent speed & $\mathrm{u}_{\mathrm{o}}$ & $\mathrm{m} / \mathrm{s}$ \\
\hline Main orifice hole area & $\mathrm{a}_{\mathrm{i}}$ & $\mathrm{m} \mathrm{f}_{\mathrm{h}}$ \\
\hline $\begin{array}{l}\text { Maximum relative displacement of the piston rod } \\
\text { with pin }\end{array}$ & $\mathrm{z}_{\mathrm{pmax}}$ & $\mathrm{m}$ \\
\hline Area of the outer hydraulic chamber & $\mathrm{k}{ }^{2}$ \\
\hline Spring constant of the tire & $\mathrm{k}$ \\
\hline
\end{tabular}

\section{PERFORMANCE ANALYSIS}

Following the above mentioned parameters and equations, the system is analysed and compared without the pin device, with existing device and with new four-tapered design. Such analysis and comparison can be obtained by using graph models for the understanding of the complete system efficiency.

In order to improve the buffer absorption efficiency, the dispersal of maximum impact energy while minimizing gear load is the goal to be attained. Specific performance criterion are considered for the design requirements in this work. The shock absorption efficiency $n_{s}$ is a first decisive factor to evaluate the buffer performance of the overall system and is given by

$$
\mathrm{n}_{\mathrm{s}}=\left(\int_{0}^{z_{\mathrm{p} \max }^{1}} \mathrm{f}_{\mathrm{s}} \mathrm{d} \mathrm{z}_{\mathrm{p}}\right) / \mathrm{f}_{\mathrm{s} \max } \times \mathrm{z}_{\mathrm{p} \max }^{1}
$$

Where, $f_{s \text { max }}$ is the maximum resisting force of the shock absorption system. Such criterion is significant for preventing structural damage as well as stability. $z_{p \max }$ is the maximum relative displacement (stroke) of the piston rod throughout the upper cylinder during the touchdown process as illustrated in figure 2 .

These factors are used as objective functions in order to maximize the buffer performance of the overall system. The new design of metering pin as illustrated in figure 4 will influence the buffer performance of the overall system for higher effectiveness. 


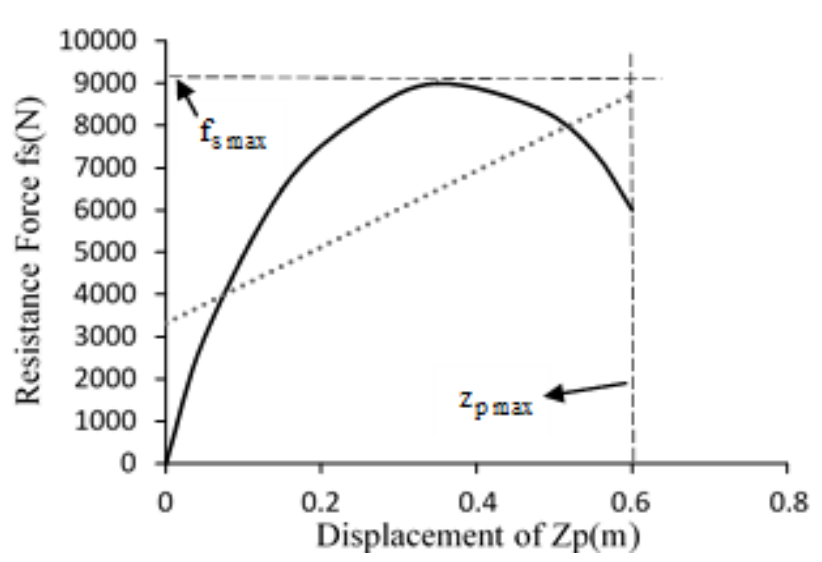

Fig. 5. Load Stroke Curve Graph

The efficiency of the shock absorber is the main criterion to evaluate the buffer performance of the system. The load deflection or the load stroke curve is utilized to determine the level of effectiveness of the system. It is defined as the ratio of the area of the load stroke curve to the area of the maximum load stroke as illustrated in fig. 5 .

Specifically, the resistive force as well as the load stroke or the displacement of the metering pin is desired to be minimised with respect to the shape in order to have maximum efficiency. The stroke curve graph is be largely improved when including a metering pin device to variate the cross section according to the load applied. The orifice cross section varies the resistive force or load by reducing it during taxiing as well as controlling it accordingly during take-off. The shape of the cross sectional metering pin provides further improvement in the functionality of the entire system as shown in fig. 6 .

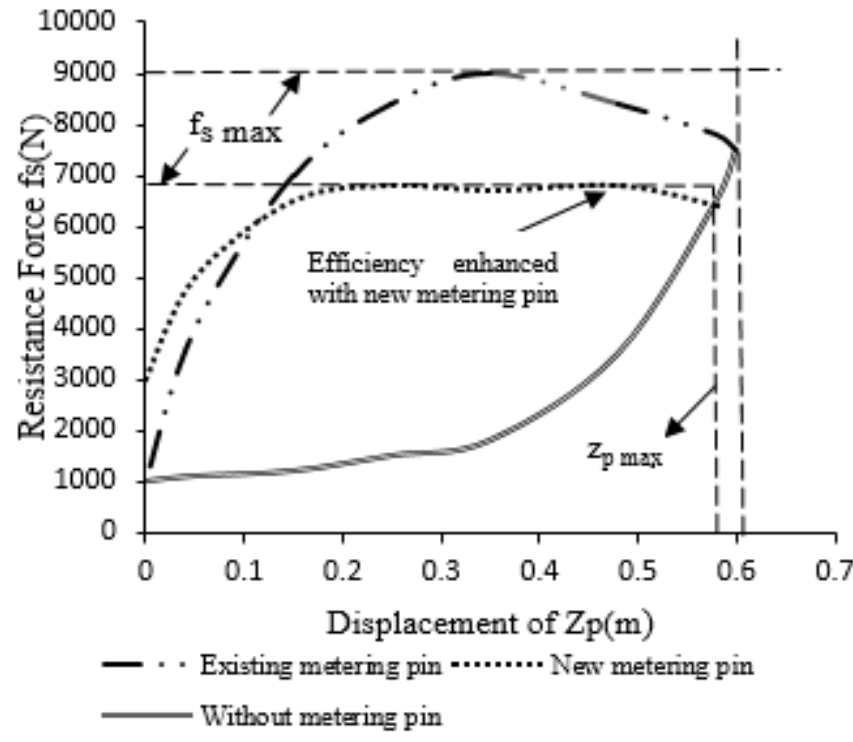

Fig. 6. Effectiveness comparison of the system

A comparison of the change in efficiency of the shock absorber without a metering pin, an existing tapered design and the new possible design is generated. The tapered metering pin provides an efficiency of above $80 \%$ and the new design of the metering pin, analysed in this research, can reach a higher value which can be above the $80 \%$ mark. The whole system achieves $10 \%$ gain when adding a metering pin and it also shows that new shape modification can bring further improvements.

\section{CONCLUSION}

The aim of this article is to demonstrate how the metering pin design could bring additional effectiveness to the efficiency of the shock absorber and to stretch out the impact in the buffer performance by changing the shape of a metering pin device. The functionality of the buffer system is to absorb most of the impact energy after the landing impact of the aircraft, which also helps in converting it into heat energy. Furthermore, it avoids overloading the buffer system due to the relatively large load and reduces the impact force on the landing gear. As a result, the right shape of the pin can bring an additional improvement in the flow of the fluid resulting in a positive upgrade. A change in the newly designed metering pin shows that its shape is an important factor which eventually results in a better effectiveness of the overall system.

To carry on research on this work in the future and to make comparisons, several phases and steps can be planned and followed. First of all, using mat lab or Simulink, a simulation model can be included. With the stated parameters, equations and explanation provided above in this paper, the simulation model can be achieved.

Would the results be promising by using the simulation model, the next phase can be directed to actual testing. This will include a pre-drop year of a landing gear with a better evaluation to be done.

The suspension system has a large scope for realistic improvement of the shape modification for the metering as well as a high degree for future upgrade. Numerous researchers have put forward the effort to start the development of buffer suspension system and bring this into consideration for various potential analysts.

\section{ACKNOWLEDGEMENT}

I am grateful to my supervisor Dr. Xue Caijun for his continuous encouragement and guidance throughout the writing of this research and my laboratory colleagues for their steady support and advice in this process. I also thank my parents, sister and friends for their help and emotional support during the COVID-19 pandemic.

\section{REFERENCES}

[1] Benjamin Chartier, Brandon Tuohy, Jefferson Retallack,Stephen Tennant, "Landing Gear Shock Absorber," 3016 Aeronautical Engineering, vol.1, November 2015.

[2] Milwitzky, B., and Cook, F. E., "Analysis of Landing Gear Behavior,' NACA Rept. 1154, 1953.

[3] Xue Caijun, Xue Xiuli, Qi Wengang, "Research on the performance of buffer for landing gear based on the drop test," Journal of Vibroengineering, Vol 14, Issue 2,2012.

[4] Yu Han, Xin Yu, Jie Huang, Cai-Jun Xue, "An experimental and numerical study on structural dynamic stress of a landing gear," Journal Of Vibroengineering, Vol 15, Issue 2, June 2013.

[5] Xiaohui Wei, Chenglong Liu, Xiangyao Liu, Hong Nie, Yizhou Shao, "Improved Model of Landing-Gear Drop Dynamics," Journal Of Aircraft Vol. 51, No. 2, April 2014.

[6] GianLucaGhiringhelli, "Testing of Semiactive Landing Gear Control for a General Aviation Aircraft," Journal of aircraft, Vol.37,No.4,August 2000 
[7] Zhou, "Design Optimization and Experimental Verification of a UAV's Landing Gear Buffer," Aircraft Engineering and Aerospace Technology, Emerald Publishing, 2019.

[8] Cai-Jun Xue, Yu Han, Wen-Gang Qi, Jian-Hua Dai "Landing-Gear Drop-Test Rig Development and Application for Light Airplanes," Journal of aircraft, Vol. 49, No. 6, December 2012.

[9] Xu Zhang, Da Song, Wenxiu Shang, Lixun Zhang, Kunlun Wu1, Yiwen Zhang, Qihe Zhang, "Simulation of a Series Double Cavity Buffer on the Landing Gear," 2nd International Forum on Electrical Engineering and Automation, 2015.

[10] ARTTU HEININEN, "Modelling And Simulation Of An Aircraft Main Landing Gear Shock Absorber," Tampere University Of Technology, 2015.
[11] Yuan Li, Jason Zheng Jiang, and Simon A. Neild, "Optimal InerterBased Shock-Strut Configurations for Landing-Gear Touchdown Performance," Journal of Aircraft Vol. 54, No. 5,2017.

[12] Fenghui Shi, "Multi-objective Optimization of Passive Shock Absorber for Landing Gear," American Journal of Mechanical Engineering, Vol 7(2), pp.79-86, 2019.

[13] Shi, F., Tanigawa, N., Koganei, R., and Maemori, K.,"Optimum TradeOff Charts Considering Mass Variation for the Design of Semi-Active and Passive Shock Absorbers for Landing Gear,"Journal of Advanced MechanicalDesign, Systems, and Manufacturing, 10(1), 1-15, 2016.

[14] Jay Patel, Drithi Shett, Ritika Menghani, S. S. Barve, "Optimization of an Oleo-Pneumatic Shock Absorber for Main Landing Gear of a Commercial Aircraft," International conference on Advances in Thermal Systems, Materials and Design Engineering,2017. 